\title{
El clero de Nueva España y las congregaciones de indios: de la evangelización inicial al III Concilio Provincial mexicano de $\mathbf{1 5 8 5}^{1}$
}

\author{
Rodolfo AgUIRRE \\ Universidad Nacional Autónoma de México \\ aguirre_rodolfo@unam.mx
}

Recepción: 6 de octubre de 2012 / Revisión: 30 de noviembre de 2012

Aceptación: 9 de enero de 2013 / Publicación: diciembre de 2013

\begin{abstract}
RESUMEN
En el presente trabajo se estudian las discusiones y propuestas de religiosos y clérigos de Nueva España sobre el problema de la dispersión territorial de la población indígena, las cuales respondían a los dos proyectos de evangelización en pugna: el de los religiosos y el de los obispos. Cada sector eclesiástico tuvo su propio concepto de lo que debían ser las congregaciones y las metas que debían cumplirse con ellas. En el único decreto que los obispos dedicaron a las congregaciones en el tercer concilio provincial mexicano de 1585 se omitió cualquier reconocimiento a la obra de los frailes en las décadas anteriores; por el contrario, los jerarcas de la Iglesia diocesana reclamaron a los virreyes la falta de cumplimiento de las cédulas reales sobre reducciones. No obstante, el modelo practicado por los frailes en las congregaciones de mediados del siglo XVI fue el que se impuso al final.
\end{abstract}

Palabras clave: congregaciones de indios, Nueva España, clero secular, clero regular, México, siglo XVI.

\section{The Clergy of New Spain and the Congregations of Indians: from the Initial Evangelization to the Third Mexican Provincial Council of 1585}

\begin{abstract}
In this paper we study the discussions among the friars and clergy of New Spain and their proposals regarding the problem of the territorial dispersion of the indigenous population. These responded to two competing projects of evangelization: the friars' and the bishops'. Each sector had its own ecclesiastical concept of what the congregations and the goals to be achieved with them should be. In the only decree destined by the bishops to the congregations, in the third Mexican Provincial Council of 1585, any recognition of the work of the friars in previous decades was omitted; on the contrary, the diocesan Church officials protested to the viceroys about the lack of compliance with the royal patents of reductions. In the end, however, the model practiced by the friars of the congregations in the mid sixteenth century prevailed.
\end{abstract}

Key words: Indian Congregations, New Spain, 16th Century, Secular Clergy, Regular Clergy, Mexico.

1 El presente trabajo forma parte del proyecto de investigación: "La Iglesia y la conformación sociopolítica de Nueva España: redes parroquiales, jerarquías eclesiásticas y actores sociales", financiado por el Programa de Apoyo a Proyectos de Investigación e Innovación Tecnológica de la Universidad Nacional Autónoma de México. Un primera versión de este trabajo se presentó como ponencia, bajo el título de "El clero y las congregaciones de indios en el III concilio mexicano" en el XI Seminario Internacional sobre el Tercer Concilio Provincial Mexicano, con sede en El Colegio de México, el 24 agosto de 2012. Agradezco también las valiosas sugerencias de los dictaminadores para mejorar este trabajo. 
Sumario: 1. Doctrinas y señoríos indígenas. 2. El virrey Velasco y las congregaciones parciales. 3. Propuestas de congregación de la Iglesia secular. 4. Las propuestas en los memoriales del tercer concilio. 5. El decreto resultante del tercer concilio. 6. Reflexiones finales. 7. Referencias bibliográficas.

La historiografía sobre congregaciones de la población indígena de Nueva España ${ }^{2}$ comúnmente acepta dos etapas: la primera, de 1550 a 1564, encabezada por el virrey Luis de Velasco y los religiosos y la segunda, de 1590 a 1604 aproximadamente, cuando las autoridades virreinales tomaron el mando actuando los frailes como simples auxiliares. Esta tesis plantea que la participación del clero, en especial los religiosos, fue importante sólo en la primera etapa y que los clérigos seculares prácticamente estuvieron ausentes en ese proceso crucial del siglo XVI. No obstante, una revisión atenta de las fuentes eclesiásticas muestra que ambos cleros se involucraron permanentemente en el asunto, ya sea congregando en ciertas jurisdicciones, o bien, proponiendo formas y métodos de actuación así como impulsando un plan general, contribuyendo así a las directrices aplicadas por la Corona española durante la segunda mitad del siglo XVI.

Si bien el clásico artículo de Gerhard sobre las congregaciones previas a 1570 dejó claro el papel protagónico de los religiosos ${ }^{3}$, es necesario retomar el asunto al constatarse que en ese proceso el clero secular también participó de una serie de discusiones y propuestas que respondieron a los dos proyectos de evangelización en pugna: la impulsada por la Iglesia regular y misionera, por un lado, y la promovida por los obispos y el clero secular, por el otro. Cada sector eclesiástico tuvo su propio concepto de lo que deberían ser las congregaciones ${ }^{4}$ y los fines que debían lograr, pues mientras que para los frailes las reducciones debían ser moderadas y siempre respetando la posesión de tierras de los indios, para el clero secular los naturales debían juntarse en grandes poblaciones y ceder las tierras que ya no les fueran útiles a los colonos españoles. Por supuesto, cada sector del clero deseaba estar al frente de la población indígena.

Por ello, al revisar el único decreto que los obispos dedicaron a las congregaciones en el tercer concilio mexicano de 1585 no es gratuito que se omitiera cualquier reconocimiento a lo realizado por los religiosos en las décadas anteriores. Esto debe llamar mucho la atención, más aún cuando en ese mismo decreto se reclamó a los virreyes el no haber obedecido las reales órdenes sobre reducciones. Sin duda, ese decreto expresaba más por lo que callaba que por lo que contenía. Las siguientes páginas están dedicadas a estudiar el papel de ambos cleros en el proceso de congregaciones hasta 1585 .

\footnotetext{
2 La congregación en el siglo XVI se entendió en Nueva España como el proceso de trasladar a los indios de su residencia tradicional, en sus tierras de cultivo y montes, a pueblos concentrados alrededor de las iglesias. Las principales investigaciones sobre la temática son: Aguirre Beltrán, 1984; Cline, 1949; Gerhard, 1977; Rubio Mañé, 1955; De la Torre Villar, 1952, 1994 y Jalpa Flores, 1993.

3 Gerhard, 1977.

4 Normalmente en Nueva España se usó el término “congregación” y en Perú el de "reducción”; en ocasiones también se usaba "junta" para designar el mismo evento. En todo caso, aquí usaremos los tres términos indistintamente.
} 


\section{DOCTRINAS Y SEÑORES INDÍGENAS}

Una vez conquistada la capital mexica en 1521 Hernán Cortés señaló al poco tiempo la conveniencia de congregar a los indios al percatarse de las dificultades de gobernar a una población con una forma de habitación tan dispersa. Diez años después esta preocupación seguía vigente. En 1531 la Real Audiencia de México explicó al rey que los indios vivían así debido a razones productivas, por lo cual debía decidirse entre conservar la organización prehispánica, no obstante las desventajas para la colonización, o bien, transformarla, pasando por alto los perjuicios que se ocasionarían a los nativos ${ }^{5}$. La decisión no era fácil.

En tanto, la evangelización avanzó en las primeras tres décadas luego de la conquista sin ninguna transformación radical del régimen prehispánico, aun y cuando algunos frailes ensayaron ya algunas reducciones. Es indudable que desde el inicio, los evangelizadores estuvieron conscientes de la necesidad que el nuevo régimen hispánico tenía de disponer de poblaciones de indios tributarios concentradas pero por entonces hubo otras prioridades además de que se carecía de un plan general, como lamentaría años después el dirigente franciscano Jerónimo de Mendieta. En su lugar, se dejó el asunto a las iniciativas personales de los evangelizadores de cada región, por lo que se realizaron algunas congregaciones parciales. Rubial explica que en diversas ocasiones la conversión iniciaba, precisamente, reduciendo a los indios de una zona en poblaciones compactas alrededor de los primeros conventos ${ }^{6}$. Ya en la década de 1530 los agustinos impulsaron algunas congregaciones en las provincias de Chilapa y Tlapa, al sur de Nueva España, una vez superado el rechazo inicial de los caciques locales ${ }^{7}$. La falta de poblaciones grandes y aglutinadas obligó a los evangelizadores a intentar visitar la multitud de caseríos de indios, tarea por demás complicada ${ }^{8}$.

De esta primera etapa de congregaciones parciales, el destacado franciscano Jerónimo de Mendieta opinó: "se hicieron muchas (...) más no fueron generales sino particulares en cual o cual parte, y allí aun no de todos los indios, porque quedaban muchos derramados" . Para este fraile había sido un error no pedir a los señores indígenas, renombrados "caciques" por la Corona, una orden general para reducir a sus gobernados, argumentando que así se hubiera logrado rápidamente y sin problemas ${ }^{10}$. Esta última observación abre la puerta para reflexionar sobre el por qué si desde el inicio de la colonización hispánica fue evidente que la dispersión indígena iba a dificultar la implantación del nuevo régimen, sin embargo la congregación general se pospuso tantos años. Una posible explicación es que, por entonces, una medida de

5 De la Torre, 1994, pp. 117-138.

6 Rubial, 1989, p. 144.

7 Lopetegui y Zubillaga, 1965, pp. 394-395.

8 Mendieta, 2002, tomo I, p. 419.

9 Ibídem, tomo II, p. 176.

10 Ibídem, tomo I, p. 176, "lo cual entonces se pudiera hacer con mucha facilidad, porque no era menester más que mandarlo a los señores y principales que gobernaban sus pueblos, que no fuera dicho cuando fuera cumplido. Y si se hubiera hecho, cosa clara es que se estuvieran los indios más dispuestos y más a mano para ser instruidos de los ministros de la Iglesia en las cosas de la fe, doctrina y costumbres cristianas y ayudados con los santos sacramentos al tiempo del menester". 
esos alcances era algo inviable debido a que se prefirió conservar el sistema tributario prehispánico, del cual dependió, al menos hasta mediados del siglo XVI, la economía de la incipiente Nueva España, incluidos los recursos para la evangelización. Para conservar ese sistema había que preservar las bases sociales y económicas de los señoríos indígenas ${ }^{11}$, una de las cuales era el trabajo y hábitat en tierras cultivables, zonas maderables y acuíferas; es decir, el asentamiento disperso y funcional para la generación del tributo ${ }^{12}$. En Perú, por la misma etapa, el conquistador Francisco Pizarro defendió también la conservación de las formas de asentamiento incaico ${ }^{13}$.

En Nueva España los frailes evangelizadores se valieron de las formas de gobierno y organización prehispánicas, a través de los caciques aliados, para reunir temporalmente a los pobladores cuantas veces fuera necesario, sin reparar por entonces en su dispersión residencial. Un segundo paso de los religiosos para organizar sus primeros centros de evangelización fue aprovechar las relaciones de dominio de los caciques sobre su población tributaria para extender el bautismo y el culto cristiano en los indios; es decir, en esta primera etapa cada convento-doctrina ${ }^{14}$ se sobrepuso a la jurisdicción de un cacique o señor natural. No es gratuito que desde $1524 \operatorname{los}$ franciscanos hayan apostado por la ayuda de los señores locales para organizar la conversión. Así por ejemplo, los primeros conventos franciscanos se construyeron en los señoríos indígenas más importantes del centro de Nueva España, como México, Texcoco, Tlaxcala o Huejotzingo, para desde ahí extenderse a otras regiones siguiendo la misma estrategia. Un quinto convento, el de Cuernavaca, sirvió de base para la extensión franciscana hacia la costa del sur ${ }^{15}$. Poco después tocó el turno a otros señoríos de segundo rango recibir a los frailes, tales como Tepeaca, Cuautitlán, Toluca o Tlalmanalco ${ }^{16}$.

Los ahora llamados caciques, con su poder aun vigente, fueron claves para el asentamiento de los frailes, la destrucción de templos y esculturas divinas, sustentar a los evangelizadores y comenzar los conventos cristianos ${ }^{17}$. Lo importante para el tema aquí tratado es advertir que, para los religiosos, iniciar a gran escala sus tareas de

11 El señorío indígena era la entidad político territorial predominante en Mesoamérica que comprendía el gobierno de un linaje sobre un número determinado de tributarios, así como el usufructo de tierras, aguas y bosques. Menegus, 1991, pp. 34-35.

12 De la Torre, 1994, pp. 123-124, ha señalado el uso que inicialmente hicieron los franciscanos de las estructuras señoriales en los inicios de la evangelización: "Aún no desaparecían del todo los grupos dirigentes, y la existencia de estos centros favorecía su acción".

13 JuRADO, 2004, p. 123.

14 El concepto de convento-doctrina se ha usado en la historiografía para designar a las unidades de evangelización y administración de sacramentos a los indios creadas por los frailes en las primeras dos décadas después de la conquista de México, que no dependían de los obispos gracias a los privilegios papales que les fueron concedidos. Morales, 2010, pp. 13-76.

15 Sin duda, los franciscanos de la década de 1570 aun tenían muy claro lo importantes que habían sido los señoríos indígenas para establecerse en la tierra, como Cuernavaca: "antiguamente era gran provincia, porque esta cabecera señoreaba muchos y buenos pueblos, en los cuales hay monasterios de las órdenes de San Domingo y de San Agustín, y aunque todo lo llaman ahora el marquesado, y todos ellos son vasallos del marqués del Valle, no esta junto ni unido como solía en cuanto al gobierno de los indios, sino todo desmembrado y cada pueblo por sí, sin tener cuenta con la cabecera” GARCíA ICAZBALCETA, 1889, p. 21.

16 Mendieta, 2002, tomo I, pp. 362 y 401.

17 Los caciques "delante de los frailes, los mismos señores y principales los quebrantaban y levantaban cruces, y señalaban lugares y sitios para edificar sus iglesias” En Coyoacán sucedió algo similar, al igual que 
evangelización no implicó por entonces la necesidad de congregar a todos los tributarios de cada señorío, si acaso a los más cercanos a las cabeceras para auxiliar en el funcionamiento de los nuevos conventos. Sin embargo, en la medida que el poder de los caciques comenzó a decaer a mediados del siglo XVI, los frailes iniciaron la creación de jurisdicciones más acordes a sus propios intereses, sin respetar ya la organización señorial. Así, varios poblados que en lo político estaban subordinados a una cabecera de cacique, fueron elevados a cabecera de doctrina por los frailes, o bien, otros que fueron elevados a cabeceras políticas, siguieron como sujetos de una cabecera eclesiástica ${ }^{18}$.

Paralelamente, el establecimiento de los cabildos indígenas, que comenzó en la década de 1540, no implicó tener que congregar, dado que siguieron usándose para las obligaciones tributarias del nuevo régimen los antiguos lazos de sujeción de la época prehispánica; es decir, no necesitaban congregar para cobrar tributos y organizar los servicios personales. Igualmente, otro proceso se inició por entonces: la creación de curatos de indios a cargo de clérigos, en regiones periféricas, o bien, a partir de pueblos sujetos de doctrinas arrebatados a los frailes. La problemática a la que se enfrentaron los clérigos fue similar: dispersión de los fieles nativos además de sólo contar con señoríos de menor rango si acaso. El surgimiento de estos curatos involucró de lleno al bajo clero secular en el asunto de las congregaciones.

Por otra parte, la libertad de movimiento de los indios decretada por la Corona fue un factor más que inhibió las congregaciones por entonces pues se contraponía al sentido impositivo de reducir a los indios en poblaciones concentradas. El primer virrey de Nueva España, Antonio de Mendoza, reconoció tal problema en las instrucciones de gobierno que dejó a su sucesor al explicar que haciéndose un pueblo, al otro día amanecía despoblado, pues los indios practicaban cotidianamente esa libertad de movimiento sin que él pudiera hacer algo al respecto:

Vuestra señoría mire bien este negocio para que no provea en él de golpe, sino después de bien entendido, poco a poco lo que le pareciere que conviene, porque de hacerse de otra manera redundarán algunos inconvenientes ${ }^{19}$.

Este tipo de política gradualista fue la que se criticaría en el tercer concilio mexicano de 1585. No obstante, otras autoridades del naciente virreinato urgían a efectuar mayores congregaciones, especialmente los obispos, desde la década de 1530. En carta de 30 de noviembre de 1537, los prelados de México, Oaxaca y Guatemala, luego de elogiar la labor de los religiosos, pedían obligar a los indios a vivir en pueblos concentrados, bajo la vigilancia del virrey y demás gobernantes pues así se podría incidir mejor en su conversión ${ }^{20}$. Cabe advertir que la responsabilidad la daban

en todos los señoríos de la laguna dulce: "y así anduvieron por todos aquellos pueblos de la laguna dulce, que son ocho principales y cabezas de otros pequeños que les son sujetos". Ibídem, tomo I, p. 416.

18 "En las grandes encomiendas múltiples como Cuauhtitlán y Chalco, la decisión eclesiástica fue de separar nuevamente a las comunidades y equilibrar mejor las doctrinas con las jurisdicciones de cabeceras indígenas". Gibson, 1991, p. 107.

19 Citado en DE La TORre, 1994, p. 129.

20 Lopetegui - Zubillaga, 1965, p. 297. 
a los funcionarios del rey, no a los religiosos, postura que ya no abandonaron en las décadas posteriores. Las discusiones al respecto se aceleraron como consecuencia de la gran epidemia de 1545-1548 ${ }^{21}$. En junta de 1546, convocada por el visitador real Tello de Sandoval, los obispos de México, Oaxaca, Guatemala, Michoacán y Chiapas, aunque aun defendieron de manera genérica la conservación de los señoríos indígenas, insistieron en la realización de una congregación general, reafirmando su necesidad y pidiendo al rey ordenar a audiencias y gobernadores organizaran el proceso $^{22}$. Además, propusieron que en tanto durara la transición se eximiera a los indios de pagar tributo o prestar servicios, idea que sería retomada décadas después.

Por su parte, el dominico fray Domingo de Santa María señaló en 1548 que varias congregaciones intentadas fracasaron por intervención de autoridades civiles y religiosas, por lo que pidió a Bartolomé de las Casas conseguir una provisión real ${ }^{23}$. Quizá en respuesta a todo lo anterior, en cédula de 1549, la Corona ordenó al virrey y la audiencia de México practicar la congregación, nombrar oficiales de república, alcaldes y regidores y que se hicieran plazas y mercados ${ }^{24}$. Sin embargo no se llegó a instrumentar una campaña general aunque sí se confirmó el nuevo papel de los obispos como autoridades responsables de regular la erección de nuevos conventos ${ }^{25} \mathrm{y}$ por tanto, de poblaciones, política que en la práctica provocaba más dificultades entre ambos cleros. ¿Cómo pensar entonces en una colaboración entre ellos para congregar a los nativos?

\section{EL VIRREY VELASCO Y LAS CONGREGACIONES PARCIALES}

El periodo que va de 1550 a 1580 fue trascendental para el futuro de la población indígena del centro de Nueva España. La administración real había ganado mucho terreno con la introducción de los corregidores y la tasación de tributos. Paralelamente, encomenderos y señores naturales fueron perdiendo poder económico y político. En cuanto a los pueblos de indios, en esta etapa se aceleró el nuevo régimen de la república de indios y las cajas de comunidad, un nuevo sistema de tributación y el repartimiento forzoso de mano de obra administrado por funcionarios reales ${ }^{26}$.

Con la decadencia del poder y autoridad de los caciques a partir de mediados del siglo $\mathrm{XVI}^{27}$, la facilidad para movilizar a los indios a los conventos-doctrina desapareció. La pérdida de autoridad de los antiguos señores prehispánicos impidió que los

\footnotetext{
21 "Los ganaderos y los agricultores españoles querían esta tierra, los encomenderos querían tributo y los frailes querían tener a sus fieles dentro de la más corta distancia. Todos convinieron que los naturales fueran reunidos en asentamientos bien dispuestos alrededor de los monasterios y todos mandaron su opinión a España”. GERHARD, 1977, p. 350.

22 Lopetegui - Zubillaga, 1965, p. 336.

23 De la Torre, 1994, p. 131.

24 Ibídem, p. 130.

25 Lopetegui - Zubillaga, 1965, pp. 336-337. Según estos autores, las resoluciones de la junta de 1546 tuvo repercusiones en la metrópoli, como la cédula de 16 de abril de 1556 , donde se pedía al virrey y la audiencia de México aplicar las propuestas de la primera.

26 García MartíneZ, 2000a, pp. 290-291.

27 Menegus, 1991, p. 76.
} 
evangelizadores siguieran concentrándolos para las grandes funciones litúrgicas de las décadas anteriores; además, todo ello se agravó por las fatales epidemias de la década de 1540. Si bien gradualmente se fueron estableciendo los cabildos indígenas, con gobernadores, alcaldes y regidores, estas entidades aun tenían que consolidarse para poder organizar a la población. Los doctrineros, y muy pronto los curas diocesanos que se fueron haciendo cargo también de evangelizar a indios, se vieron aun más presionados para visitar la multitud de pequeños caseríos sujetos a las cabeceras de doctrina y parroquiales ${ }^{28}$. Pronto se concluyó que era materialmente imposible ejercer una acción evangelizadora eficaz y permanente sin introducir cambios radicales en la organización social indígena. En 1552, fray Pedro de Gante, pionero de la evangelización en el centro de Nueva España, tuvo que reconocer que la continuidad de los cultos religiosos prehispánicos se debía a la dispersión de los indios ${ }^{29}$. Para la Corona la necesidad de reducir a los indios aumentó al advertirse lo difícil que era gobernar y cobrar tributos en una población nativa dispersa.

A mediados del siglo XVI, el nuevo virrey Luis de Velasco llegó con instrucciones concretas para avanzar en el asunto, lo cual se tradujo en apoyarse en las órdenes religiosas, a despecho de los obispos:

seleccionando y visitando nuevos sitios para los monasterios y planeando cabecera y pueblos de visita, formulando ordenanzas que anticipaban problemas y que trataban de los detalles de la vida comunal. En algunas ocasiones varias cabeceras fueron reunidas en un solo sitio para compartir la parroquia, el mercado, etc. ${ }^{30}$.

Aunque Velasco señaló también la contradicción entre libertad de movimiento y lo forzoso de las congregaciones, como antes el virrey Mendoza, sin embargo inició desde 1550 algunos ensayos de congregación aunque sin todo el éxito esperado ${ }^{31}$. No faltaron opiniones en contra de tales acciones, como la del oidor Vasco de Puga, quien acusó que las reducciones fueron hechas sin orden y contra la voluntad de los indios. Otro oidor fue acusado por Jerónimo de Mendieta de estorbar la congregación que él mismo había organizado en Calimaya ${ }^{32}$. De hecho, el franciscano expresaba el poco alcance que hasta entonces habían tenido las reducciones intentadas:

no se hace pueblo de nuevo que sea fijo, ni acaba ninguno de ellos de tener asiento, porque andan los indios (como ven que no hay fuerza) vagueando y jugando a págome no me pago, y háceseles a los pobres sin comparación en esto mucho mayor agravio que en derribarles sus casas viejas, porque hacen veinte veces las nuevas y tantas las deshacen, y ándanse mudando hitos sin tomar en alguna parte asiento ${ }^{33}$.

\footnotetext{
28 Gibson, 1991, p. 37, ya había llamado la atención sobre esta crucial estrategia de los primeros evangelizadores para facilitar la conversión,

29 Carta de fray Pedro de Gante al rey. México, 15-II-1552. Cartas de indias, 1877, p. 101.

30 Gerhard, 1977, p. 350.

31 De la Torre, 1994, p. 132.

32 CARTAS..., 1886, p. 28.

33 Ibídem, p. 29.
} 
El franciscano pidió además que a cada nuevo poblado se le diesen dehesas y ejidos para su labranza y no como en Tacuba, en donde los españoles habían arrebatado todas sus tierras a los indios. El mensaje de Mendieta era claro: de nada servía que los religiosos se esforzaran en hacer reducciones si las otras autoridades no coincidían en el mismo objetivo; por ello, agregaba, las reducciones no podían hacerse sin antes asegurar a los indios la posesión de sus tierras de cultivo. En este sentido, el franciscano denunciaba las intenciones de los españoles de aprovechar las congregaciones para obtener más heredades:

Más es tanta la codicia y poca cristiandad de algunas particulares personas a quien la ejecución de este negocio se ha cometido, que no han tenido ojo sino a apañar lo que podían, arrinconando a los indios en las peores tierras y dejando las mejores vacías, con esperanza de entrar ellos u otros sus amigos en ellas, que era ocasión de desbaratarse los indios y cesar la junta de los pueblos ${ }^{34}$.

Ante todo ello, Mendieta insistió en que el rey debía ordenar de oficio las juntas y quitar todos los obstáculos para lograrlas, tanto materiales (arrasar los caseríos antiguos de los indios) como de autoridades. El enérgico involucramiento de los frailes en las primeras congregaciones no dejó de causarles también ataques y críticas, como expresaron los mismos al rey en 1561:

También se quejan de nosotros y es lenguaje y aun muy general, que los hemos sacado de los montes y quebradas y de venados, hechos corderos mansos y recogidos en poblaciones y policía, diciéndoles ser para su bien espiritual y temporal: dicen ahora que los hemos engañado, que no ha sido sino para contarlos cada día, como se hace y añadirles tributos y servirse de ellos los cristianos, de los cuales habían huido y por tomarles las tierras que en sus valles y montes y quebradas las labraban para estancias y pastos de ganados y que no les queda sino volverse otra vez a los montes ${ }^{35}$.

No obstante, virrey y religiosos siguieron adelante, aunque sin un plan general. En 1559, Velasco explicaba que:

en las provincias y pueblos que he visitado en esta Nueva España $[\ldots]$ he dado orden cómo se junten los pueblos en traza cerca de las iglesias y monasterios con parecer de los religiosos que andaban en mi compañía, y se han hecho fuentes y puentes y abierto caminos donde ha convenido, y se han señalado a todos los pueblos dehesas y ejidos para sus ganados sin daño de sus sementeras [...] ha sido la cosa más necesaria para su bien espiritual que en la tierra se ha hecho, porque es cierto que, como estaban dispersos por montes, sierras y barrancas, no se podía tener cuenta con el patrimonio de Jesucristo ni con el de vuestra majestad ${ }^{36}$.

\footnotetext{
34 Ibídem, pp. 161-162. En 1560 la Corona insistió en su orden de congregar, pidiendo respetar las tierras a los indios. Ver: De LA TorRe, 1994, p. 133.

35 Carta al Rey D. Felipe de los provinciales de las órdenes de Santo Domingo, San Francisco y San Agustín justificándose de los excesos que se les atribuían. México, 25-II-1561. CARTAS..., 1877, p. 150.

36 Citado en Gerhard, 1977, pp. 352-353.
} 
A pesar de estos avances, las dificultades seguían presentándose, incluso entre las mismas órdenes religiosas por cuestiones políticas y de rivalidad. En 1557, cuando los agustinos de Acolman quisieron construir convento en el pueblo sujeto de Teotihuacán, los caciques y la población los rechazaron, aun y cuando los primeros tenían el apoyo del virrey y de la mitra. Ante el castigo a los caciques por encabezar la resistencia, los indios despoblaron Teotihuacán; en consecuencia, los agustinos tuvieron que ceder y los franciscanos se hicieron cargo de recongregar ${ }^{37}$.

Con las congregaciones fomentadas por el virrey Velasco, los frailes reajustaron sus doctrinas, agregando o quitando pueblos de visita, o bien, estableciendo nuevas cabeceras $^{38}$. No faltaron pueblos pequeños que, elevados a cabeceras de doctrina, quisieron convertirse en cabeceras políticas independizándose de sus antiguos centros prehispánicos ${ }^{39}$. Según Gerhard, si bien la meta inicial de los frailes era fundar una doctrina por cada pueblo congregado, según el método empleado en Perú, ante la resistencia de los nativos, optaron más por el patrón de cabecera-sujetos ${ }^{40}$. Aunque para este mismo autor la etapa congregadora del virrey Velasco fue todo un éxito, Jerónimo de Mendieta expresó algo diferente:

Verdad es que algunos y no pocos de los religiosos miraron en esto, y lo advirtieron a los que gobernaban, y con su favor (sobre todos los cuidados y trabajos que tenían en lo espiritual) se esforzaron a juntar los indios en poblaciones, cada uno a donde residía y así se hicieron muchas, como las hay el día de hoy, que todas fueron hechas por su mano; más no fueron generales, sino particulares en cual o cual parte y allí aun no de todos los indios, porque quedaban muchos derramados ${ }^{41}$.

Como se puede apreciar, la tendencia en la época del virrey Velasco fue entonces una solución intermedia: formar pueblos o estancias de visita, tantas como fueran necesarias, para no alejar demasiado a los campesinos de sus formas tradicionales de subsistencia y defender sus tierras de la ofensiva de los colonos ibéricos. La creación de los pueblos sujetos estuvo estrechamente ligada a la decisión de los religiosos de pactar con los indios y sus gobernantes congregaciones parciales, con el fin de proteger sus tierras de cultivo. Sin duda, la multiplicación de ermitas tuvo objetivos defensivos de los indios, como explicó en 1569 un cura sobre la singular característica de un pueblo sujeto al curato de Texcaltitlán:

Los Reyes no tienen indios ningunos, más que los mismos indios de San Andrés; hicieron a dos tiros de arcabuz, en una cabaña, esta iglesia y cuatro casas alrededor y sembraron alrededor de las casas e iglesia una sementera de maíz porque aquellas tierras no las pidan los españoles por baldías. Esta ermita y todas las otras arriba referidas los indios las edificaron de su autoridad ${ }^{42}$.

\footnotetext{
37 Mendieta, 2002, tomo I, pp. 521-526.

38 GiBson, 1991, pp. 108-109.

39 Ibídem, p. 58.

40 Ibídem, p. 386.

41 Mendieta, 2002, tomo II, p. 176.

42 Descripción..., 1976, p. 217.
} 
Los mismos indios de Texcaltitlán creaban pueblos sujetos con sus pequeñas iglesias a conveniencia, como la estancia de San Martín: "Esta iglesia y estancia cada año la mudan por una sabana grande, arriba y abajo y hacen la iglesia y casas de su motivo, porque los españoles no la pidan por baldía"43. En 1570, el cura del real de Ixmiquilpan señaló en su informe la preferencia de indios por poblar, más que en la cabecera parroquial, en sitios alternos, bajo el mando de indios principales ${ }^{44}$. El de Hueypoxtla se quejaba también de que en la cabecera parroquial sólo había 100 casas, pues el resto de los fieles seguían viviendo en sus tierras de cultivo ${ }^{45}$. La multiplicación de capillas, ermitas e iglesias sujetas habría tenido entonces como motor el anterior acuerdo y en este sentido, el patrón de congregaciones que predominó en Nueva España estuvo determinado por ese factor ${ }^{46}$.

El proceso de creación de los pueblos de visita debe investigarse mejor porque, sin duda, fueron las entidades más dinámicas en la conformación de las jurisdicciones parroquiales, más que las poblaciones elegidas como cabeceras eclesiásticas, en términos generales, más estables. A partir de entonces, el binomio cabecera-sujeto fue inseparable en las redes parroquiales. Mendieta señala al respecto que sólo en la provincia del Santo Evangelio podían sumar hasta 1000 pueblos sujetos o de visita ${ }^{47}$.

Llegado a este punto, cabe destacar que la Iglesia secular trató también de beneficiarse de este tipo de organización parroquial. Desde la década de 1550, el arzobispo de México, Alonso de Montúfar, comenzó a nombrar curas diocesanos en aquellos pueblos sujetos a doctrinas muy alejados de sus respectivas cabeceras provocando el enojo de los religiosos ${ }^{48}$. Esta política del arzobispado apoyaba, sin desearlo así, la consolidación del binomio cabecera-sujeto como vía de acceso del clero secular a la administración de indios, retrasando igualmente una mayor congregación de los indios. El clero parroquial diocesano también participó de esta tendencia. Por ejemplo, el cura de Tlachichilpa, en el valle de Toluca, abogó por la congregación parcial en sujetos ante la gran dispersión de los caseríos dispersos de su parroquia ${ }^{49}$. Otro

43 Ibídem, p. 218.

44 Ibídem, p. 65.

45 Ibídem, p. 89.

46 El cura de Tepozotlán explicaba lo siguiente en 1569: "Estas dichas ermitas y algunas iglesias mandaron hacer frailes de San Francisco cuando visitaban este dicho pueblo de Tepotzotlán, y así se han quedado hasta ahora. Dícese misa en las ermitas cada año, el día de la fiesta del santo de la ermita”. Ibídem, p. 84.

47 "Cada uno de los conventos de religiosos, y de los partidos de clérigos, tiene de visita muchas iglesias en pueblos y aldeas que están a cargo de su doctrina. Estas iglesias sería imposible poderlas yo ni otro alguno contar; mas por las que esta provincia del Santo Evangelio tiene de visita (que serán más de mil), se podrá considerar las muchas que habrá en las otras cuatro provincias de esta mesma orden, y en las de las otras órdenes, y en los partidos de los obispados que aquí se han relatado”. MENDIETA, 2002, tomo II p. 236

48 Morales, 2010, p. 46.

49 "Hase dicho misa por los vicarios pasados en las más ermitas. Están los indios muy derramados, que no son pueblos sujetos, porque hay sujetos que tienen las casas apartadas, unas de otras, más de media legua y en algunas estanzuelas, como está referido, hay a seis indios. Son pocos y están muy derramados, y la mitad de ellos metidos en los montes en diversas partes. Viven mal y no tiene la doctrina que han menester, ni se les pueden dar los sacramentos porque viven como bárbaros y no hay quien acuda a dar aviso al cura de las necesidades que ocurren. Pueden en las dichas partes idolatrar sin que se sepa ni entienda. Descargarán su real majestad y vuestra señoría reverendísima las conciencias en mandarlos reducir a los sujetos más cercanos, en lo cual habría remedio a lo dicho". DESCRIPCIÓN..., 1976, p. 157, 
cura, el de Tepozotlán, hablaba de pasar de pequeños caseríos alrededor de ermitas a estancias sujetas más grandes ${ }^{50}$.

Así, entre 1550-1564, se habrían formado en el centro de Nueva España una red de nuevas poblaciones, organizados en cabeceras y sujetos para los fines de la administración espiritual. La Iglesia quiso aprovechar al máximo este logro: si Valderrama impuso el tributo personal y se hicieron ahora padrones de tributarios, el clero parroquial comenzó a registrar a cada indio fiel; ante la baja demográfica había que conocer con mayor precisión el número de habitantes de cada parroquia. De ahí que desde la década de 1560 comenzó a ser útil saber el número de confesantes y de tributarios por igual para el clero parroquial. Los padrones parroquiales comenzaron a ser muy importantes para tomar decisiones, para saber el tamaño de la feligresía y sopesar el crecimiento o disminución de la parroquia. Los doctrineros organizaron todo un ejército de indios auxiliares de las doctrinas encargados de vigilar a los pueblos de visita. A fin de cuentas, lo importante fue que religiosos y virrey Velasco consolidaron el modelo de congregación basado en cabeceras y múltiples sujetos, una solución moderada frente a quienes pugnaban por una reducción más radical, con poblaciones más grandes y sin sujetos. La formación de cabeceras y sujetos antes del tercer concilio fue una etapa crucial en el largo proceso de conformación parroquial. El siguiente reto fue cómo dar estabilidad a esa red de doctrinas y curatos en medio de tantos cambios, incertidumbres sociales y disputas por el poder a todos los niveles.

\section{PROPUESTAS DE CONGREGACIÓN DE LA IGLESIA SECULAR}

El asunto de las congregaciones fue retomado por los obispos de Nueva España durante la realización del primer concilio mexicano de 1555. El decreto resultante recogió buena parte de lo discutido y acordado en juntas eclesiásticas previas ${ }^{51}$, omitiendo

\footnotetext{
50 "Podríanse derribar algunas destas ermitas, y que la gente della se congregase a las estancias principales, porque cada año que se hace alguna fiesta destas ermitas se echan derramas excesivas entre los naturales para las dichas fiestas, y habiendo pocas ermitas habría pocas fiestas en el año, y echarse hian pocas derramas para ella; y estando congregados los dichos naturales en sus lugares y estancias principales, se podrían los enfermos mejor confesar, que como están, lejos y derramados". Ibídem, p. 84.

51 I y II concilios, 2004, sesión LXXIII: "Que los indios se junten en pueblos y vivan políticamente" "Grandes inconvenientes se hallan de vivir los indios tan derramados y apartados unos de otros por los campos, montes y sierras, y donde muchos de ellos viven más como bestias que como hombres racionales y políticos, de donde se sigue que con gran dificultad son instruidos y enseñados en las cosas de nuestra santa fe católica y en las humanas y políticas. Y porque para ser verdaderamente cristianos y políticos, como hombres racionales que son, es necesario estar congregados y reducidos en pueblos y lugares cómodos y convenientes, y que no vivan derramados y dispersos por las sierras y montes, y no sean privados de todo beneficio espiritual y temporal, sin poder tener socorro de ningún bien; sancto approbante concilio, estatuimos y ordenamos que los dichos indios sean persuadidos y, si menester fuere, compelidos por la justicia real, con la menos vejación que ser pueda, a que se congreguen en lugares convenientes y en pueblos acomodados, donde vivan política y cristianamente, y les puedan ser administrados los santos sacramentos y puedan ser instruidos y enseñados en las cosas necesarias a su salvación, y puedan ser socorridos en sus enfermedades y necesidades y tengan quien les ayude a bien morir, y entre ellos haya oportunidad de ejercitar las obras de piedad y misericordia; para lo cual este santo concilio suplica a su majestad, y en su nombre al muy ilustre virrey y audiencia real, manden y provean cómo esta junta y congregación de pueblos tenga efecto como su majestad por sus reales cédulas e instrucciones lo tiene proveído y mandado, pues tanto importa a la salvación de las ánimas de estos naturales y
} 
en cambio toda alusión a lo ensayado en el asunto por los religiosos. En contraste, el franciscano Mendieta defendía esto último así:

¿qué ciudad se ha fundado, qué pueblo se ha juntado, qué república se ha ordenado, qué traza se ha dado, qué iglesia o hospital se ha edificado, qué paces o conciertos se han hecho, qué dificultades se han allanado, qué todo ello no ha sido con pies y manos de religiosos? ${ }^{52}$.

No bien terminó la gestión del primer virrey Velasco en 1564 cuando se comenzó una nueva etapa de reflexiones y propuestas sobre el asunto que llegaron hasta el mismo Consejo de Indias por medio de su visitador Juan de Ovando, quien se interesó mucho en las problemáticas eclesiásticas. A raíz de la llamada Junta Magna de 1568, encargada de discutir, analizar y proponer soluciones para los principales problemas de las Indias, los asuntos eclesiásticos y de evangelización estuvieron muy presentes ${ }^{53}$. En consecuencia, Ovando solicitó a los obispos informes puntuales sobre el estado que guardaban sus jurisdicciones.

Los informes que varios curas diocesanos enviaron en 1569, a petición del arzobispo de México, Alonso de Montúfar, para informar al visitador Ovando sobre el estado de sus jurisdicciones, dan cuenta del grado en que los mismos compartían ya con los frailes dificultades similares para administrar y conocer mejor a sus fieles, partiendo de parroquias conformadas por múltiples poblados pequeños, a veces muy alejados de las cabeceras. ¿Cómo administrar eficazmente a tantos pueblos sujetos dispersos, rebeldes en ocasiones y con idiomas poco conocidos por el clero? Sin duda, las reducciones de la era de Velasco fueron una solución parcial que no terminó con los problemas de atención y comunicación. ¿Cómo lograr la integración de las partes al todo, sobre todo cuando se hablaban diferentes lenguas y coexistían diferencias culturales? El cura de Tenalcingo así lo hacía saber al arzobispo Montúfar:

Tienes esta cabecera una estancia que se dice Tenalcingo, que fue rebelde poco ha en no querer obedecer a la cabecera, porque ella juntamente con dos estancias, que se dice la una San Jerónimo y la otra San Francisco, trujeron pleito con su cabecera, el dicho Tenancingo, por ser cabecera, lo cual esta llano [...] Tienen estas tres estancias setenta vecinos, de la cual hay diez que entienden la lengua y se confiesan y mujer ninguna [...] Hay otro sujeto que se dice Chiapa y la iglesia San Juan; hay en él dos principales, uno de lengua chontal y otro izcuca; tiene cada uno en forma de cargo y cuidado cuarenta vecinos de su lengua, hay entre ellos hasta seis indios que se confiesan [...] Hay otra estancia que se dice Ichpuchquila, tiene veinte indios, de los cuales se confiesan dos [...] Hay otra que se dice Aguacatitlan, tiene veintitrés indios y de confesión seis [...] Otra se dice Alxixauhya [...] tiene veintiséis vecinos y de confesión cuatro [...] Otra que se dice Ahuchuetla [...] tiene quince indios, son de confesión

a su buen gobierno espiritual y temporal. Y en la ejecución de lo sobredicho pongan los diocesanos, cada uno en su obispado, muy gran diligencia en que los indios se junten, porque no será pequeña predicación trabajar de primero hacer los hombres políticos y humanos, que no sobre costumbres ferinas fundar la fe, que consigo trae por ornato la vida política y conversación cristiana y humana".

52 Cartas..., 1886, p. 16.

53 García Martínez, 2000b, pp. 298-300. 
seis. Otra se dice Acateupa, tiene quince indios y de confesión los diez [...] Otra se dice Acateupa tiene quince vecinos y de confesión los diez [...] otra que se dice Tetanaco, tiene veinte indios y de ellos son de confesión cuatro ${ }^{54}$.

El cura advertía que no confesaba a quienes no hablaban mexicano, pero creía que todos sus feligreses ya estaban convertidos y aceptaban el cristianismo, además de que ya no idolatraban. En Huayacocotla, el vicario diocesano desconocía muchas cosas de su partido, incluyendo el número de fieles ${ }^{55}$. Por ello, se apoyaba en el padrón de tributarios:

por esta tasación me aprovecho y uso para empadronar mis feligreses y por esta el fiscal y señalados para esto la toman al mayordomo que tiene cargo de cada pueblo e por esta me rijo para administrar la doctrina cristiana, y asimismo para declaración de esta cuenta y para poder mejor saber la gente que hay. Porque de otra manera es imposible porque moran en sus pueblos ellos muy apartados unos de otros, tanto que para ver de hacer la iglesia cortan un pedazo de sierra ${ }^{56}$.

La dispersión de los caseríos indígenas hizo que algunos curas solicitaran la subdivisión de sus curatos, ante la imposibilidad de atender a todos, como el de Zumpango:

Hay necesidad que este partido se divida en dos ministros, que por estar la gente muy derramada y ser mucha, no acuden todos a la doctrina. En Zumpango y Citlaltepec puede estar un ministro, y en Xaltoca y en Tlalpan y el pueblo de Tecama, que está media legua de Xaltoca y es visita de los padres agustinos que residen en el pueblo de Aculma puede haber otro ministro y todos son de su majestad y ojalá basten aun para lo que hay que hacer ${ }^{57}$.

En los curatos asentados en minas, el asentamieno humano tampoco era una garantía. La siguiente descripción de la población flotante de las minas de Pachuca puede ser un patrón para entender los problemas de cohesión social en parroquias de reales mineros:

todos estos dichos indios son advenedizos y gente que no permanecen en un lugar: ellos se van y vienen donde quieren, según andan las minas, buenas o malas y así unas veces hay más y otras menos ${ }^{58}$.

El provisor de indios del arzobispado insistió, por su parte, en una mayor congregación para estructurar mejor la red parroquial así como en una distribución proporcional del número de fieles por jurisdicción. Este ministro de la curia, en contraste con religiosos como Mendieta, opinaba que la dispersión indígena provocaba la ocupación de muchas tierras que no se aprovechaban bien, además de que dificultaba la

54 Descripción..., 1976, p. 244.

55 Ibídem, p. 248.

56 Ibídem, p. 249.

57 Ibídem, p. 92.

58 Ibídem, p. 201. 
labor de los doctrineros; por ello, proponía que en cada partido se hicieran sólo una o dos poblaciones atendidas por un solo ministro ${ }^{59}$. En otras palabras, este alto funcionario de la mitra pedía una mayor concentración de los fieles y terminar con el gran número de pueblos sujetos pequeños.

El arzobispo Alonso de Montúfar tenía sus propias opiniones y proyectos al respecto: los indios dispersos tenían más oportunidad de conspirar y rebelarse, por lo cual debían acabar de congregarse todos los indios en poblaciones mayores "con suavidad y buena traza y acuerdo se ordenase generalmente, que todos los indios viviesen en poblaciones formadas", todo bajo el mando concertado de los ministros eclesiásticos y seculares, gobernadores, caciques y mandones de indios:

creo que se haría con facilidad y brevedad, aprobando ellos el modo que se había de tener en la ejecución, que como personas que tienen la cosa presente, mirarían mejor las circunstancias, atrayendo a los maceguales, que en todo siguen su parecer, a que se esforzasen y animasen a cumplir lo que se les mandase por el virrey; porque negocio tan general y sus semejantes, mejor suceso tienen y aplauso, en opinión del pueblo, cuando se comunica con muchos que pueden ayudar al intento ${ }^{60}$.

Con todo ello, continuaba el prelado, se terminaría con idolatrías y pecados a que conllevaba la soledad, además de que aprenderían oficios útiles para desterrar su holgazanería y la falta de bastimentos y granos. Para Montúfar, a diferencia de los franciscanos, los indios tenían muchas tierras sin cultivar, desaprovechadas, que los españoles necesitaban para su sustento. El mismo prelado criticaba que debido a la dispersión indígena había un manejo discrecional de sus tributos y su trabajo, por lo cual se había excedido el número de iglesias y ermitas:

negocio que mucho los ocupa y consume, especialmente los soberbios edificios de los religiosos, que son de calidad, que en algunas partes se pueden decir todos los indios siervos adscripticios de sus casas, edificando cada prior, guardián o vicario á su modo, derribando y haciendo por antojo lo que les parece, como no les cuesta más que mandarlo; $y$ en esta materia los clérigos son más moderados, porque proceden con licencia limitada, que esta no tienen ni guardan los religiosos, que debe vuestra majestad mandar remediar [...] porque sus edificios son tan costosos y derramados, que ni servirán para el clérigo ni para la comunidad de los indios, como se ha visto en algunos monasterios que han dejado, que es lástima considerar su perdición que se deja bien entender, haciendo monasterio para dos o tres frailes, que es tan de ordinario capaz en sus claustros, celdas y huertas para cincuenta, con color que podría haber capitulo en él, o estudio o otras imaginaciones arbitrarias; y aunque hay razón para que ellos tengan morada capaz, falta para tan notable exceso ${ }^{61}$.

\footnotetext{
59 "Convendría que a cada clérigo o religioso se le señalase el partido y cantidad de feligreses que cómodamente puedan tener, porque es cierto y muy público y notorio que hay muchas provincias donde hay mucho menos ministros de los que son menester, y así mueren cantidad de criaturas sin el santo bautismo y adultos sin confesión”. Ibídem, p. 280.

60 Ibídem, p. 201.

61 Ibídem, pp. 202-203.
} 
Como es posible apreciar, la Iglesia secular veía mal que los frailes siguieran decidiendo por ellos mismos dónde construir conventos o dónde derribarlos, así como de disponer de la mano de obra indígena.

Años más tarde, el sucesor de Montúfar en México, Pedro Moya de Contreras, reafirmaba la postura de la mitra arzobispal en cuanto al traspaso de tierras de indios a españoles a raíz de las congregaciones:

cualquier aumento de vecinos no les sería disminución en sus propiedades por los muchos baldíos que tienen y de esto resultaría haber más comodidad para hacer granjerías los españoles en las tierras que ellos dejasen, por no poderlos beneficiar, haciendo alguna justa recompensa a los indios ${ }^{62}$.

Es indudable que la pugna de las Iglesias secular y regular no se trataba solamente por el poder y la autoridad sobre los fieles sino también contenía implícita dos visiones sobre el futuro de Nueva España.

\section{LAS PROPUESTAS EN LOS MEMORIALES DEL TERCER CONCILIO}

Para cuando se desarrolló el tercer concilio provincial en la ciudad de México, en $1585^{63}$, el asunto de las congregaciones de indios tenía ya medio siglo de intentos, propuestas y discusiones al seno de ambos cleros; aunque en términos generales, frailes y clérigos coincidían en su necesidad había diferencias importantes entre unas propuestas y otras, como se ha mencionado ya. De ahí que no resulte extraño que en las discusiones y memoriales que se presentaron durante las sesiones conciliares se haya abordado también la problemática de las reducciones, surgiendo proposiciones sustanciales que serían retomadas en la etapa definitiva de fines del siglo XVI. En general, ambo cleros coincidieron en lograr la uniformidad y la residencia permanente de los indios en pueblos concentrados alrededor de las iglesias; es decir, privilegiando las necesidades de la administración espiritual. La obtención sistemática de derechos parroquiales implicaba tener a los fieles convenientemente congregados en espacios planificados y accesibles, algo que aun estaba lejos de alcanzarse en varias diócesis y menos aún luego de la gran epidemia de 1576.

La propuesta más desarrollada en el concilio de 1585 fue la del jesuita Juan de la Plaza, quien tuvo como modelo el de las parroquias establecidas en la provincia peruana de Chucuito. Ahí, explicaba el jesuita, los indios se agruparon en siete pueblos grandes, cada uno con tres o cuatro clérigos con igual número de iglesias; es decir, no se hicieron cabeceras y pueblos satélites, como en Nueva España. Mencionaba el nombramiento de un visitador para congregar, quien en compañía del corregidor, el cura y el cacique o gobernador de indios:

62 Carta del arzobispo de México D. Pedro de Moya y Contreras al Rey Don Felipe II, dándole cuenta de su visita á la Huasteca y provincia de Panuco. México, 24-IV-1579. Cartas de Indias, 1877, p. 222.

63 Investigaciones recientes sobre el tercer concilio mexicano en MARTínEz y CERVANTES, 2005. 
trataban y conferían en cuántos pueblos se podía reducir aquella provincia, mirando la distancia de ella y la más cómoda habitación en el asiento saludable y mejor provisión de agua, tierras para sembrar y pastos para el ganado; $\mathrm{y}$, conforme el número de pueblos pequeños que había en la provincia, señalaban el número de pueblos principales en que se podían juntar toda la provincia y enviaban relación particular de esto al virrey ${ }^{64}$.

Los indios edificaron sus casas cuando no tuvieron trabajo en la tierra y se les perdonó la mitad del tributo mientras duró la congregación. En cada provincia del virreinato se hicieron sólo seis u ocho pueblos grandes. Respecto a la organización de los curas, continuaba Plaza, se había nombrado a uno por cada 500 casas:

En los pueblos donde se ponían dos o más clérigos, se edificaban otras tantas iglesias, como se pusieron clérigos, para que cada clérigo tuviese su parroquia y conociese sus parroquianos [...] Y por esto se hicieron diferentes iglesias en distancia conveniente para repartir los indios en cada un barrio a su parroquia y que cada barrio tuviese su clérigo conocido y su iglesia, adonde acudiesen los indios a oír misa y a recibir los sacramentos y a aprender la doctrina cristiana ${ }^{65}$.

Algo similar se hizo en la provincia de Potosí, en donde se crearon 14 parroquias, si bien ahí se nombraron a miembros de los dos cleros ${ }^{66}$. Para el caso de Nueva España, esta idea de crear parroquias con igual número de fieles favorecería la creación de más beneficios para el clero secular pero perjudicaría a las grandes doctrinas de los religiosos al tener que subdividirse. No es casual que Juan de la Plaza haya insistido en implantar el modelo peruano de congregaciones. En la década de 1570 el enérgico virrey Francisco de Toledo organizó toda una campaña de reducciones en zonas indígenas vitales para el futuro del régimen colonial peruano que dio como resultado la formación de 1000 pueblos y 712 doctrinas $^{67}$.

Para el obispo de Chiapa, fray Pedro de Feria, la dispersión indígena sólo provocaba la conservación de los ritos y supersticiones antiguas, no podían ser visitados convenientemente y su lejanía facilitaba al "diablo" seguir disponiendo de los indios. Por ello, pedía que con rigor se procediera a juntarlos en pueblos grandes, hasta donde fuera posible. Los lugares de los nuevos pueblos debían ser cómodos, sanos y con suficiente agua; para esa tarea alcaldes mayores y ministros eclesiásticos debían actuar en conjunto. Para evitar la fuga de los indios sería necesario pedir a las autoridades locales aprehender y reducir a sus pueblos a todos los indios renuentes a vivir

64 Manuscritos del concilio tercero provincial mexicano (1585), 2006, primer tomo, vol. I, p. 274. De hecho, en el tercer concilio limense se dio el derecho a los obispos para congregar a indios en parroquias de incluso 200 o 300 indios. Véase también Pérez Puente, 2010, p. 108.

65 Manuscritos del concilio tercero provincial mexicano (1585), 2006, primer tomo, vol. I, p. 275.

66 Ibídem, p. 277.

67 "La Visita dio como resultado un total de 614 repartimientos, 712 doctrinas y más de 1000 reducciones o pueblos de indios (Málaga Medina, 1993, p. 299). Los encargados de visitar la tierra, nombrados por el mismo Virrey, incluían oidores y fiscales de las Audiencias de Lima y Charcas, capitanes, miembros de la órdenes de caballería, profesionales y destacados vecinos de las principales ciudades quienes, acompañados por visitadores eclesiásticos, un alguacil, un escribano y un intérprete, deberían trasladarse personalmente a huaycos y quebradas en busca de los indios". JuRADO, 2004, p. 127. 
reducidos pues de esa manera el resto de los naturales entenderían que de "ninguna manera se han de poder librar ni excusar" ${ }^{68}$. Como otros personajes, el obispo Feria pedía perdonarles al menos un año de tributo mientras se hacía la congregación. Respecto a que muchos indios permanecían en zonas alejadas cuidando sus tierras, el prelado pedía a la autoridad real garantizarles su integridad para que ya no se negaran a concentrarse "porque si esto no se hace, habrá cada día mil pleitos y turbaciones y pendencias entre los indios" 69 .

Otro consultor del concilio, el catedrático de la Real Universidad de México Hernando Ortiz de Hinojosa enumeró las ventajas que para la conversión y cura de almas produciría la congregación de los indios:

lo primero que les podrán llevar los sacramentos de la eucaristía y extrema unción a sus casas sin mucho trabajo. Lo segundo, que los ministros podrán tener cuenta con sus ovejas y remediarles sus necesidades espirituales. Lo tercero, que se harán más mansos y más sociables. Lo cuarto, que se evitarán muchas ofensas de Dios, que se hacen estando apartados y enriscados en los cerros y hundidos en las quebradas y lomas de los montes, y escondidos en las cuevas y cavernas de la tierra, huyendo de la conversación humana, tan natural a los hombres racionales; todo a fin que no les vean hacer sus pecados y cometer delitos, hasta idolatría, de la cual es apto lugar el monte ${ }^{70}$.

Ortiz de Hinojosa criticaba el perjuicio que para la conversión cristiana de los indios ocasionaba la existencia de múltiples ermitas

porque se han hecho tantas que no hay barrio ninguno de indios donde no haya una, que es la polilla y la destrucción de estos naturales, por las derramas que se echan por cabezas todas las veces que en ella se han de celebrar sus fiestas ${ }^{71}$.

Por todo ello, el catedrático pedía derribar todas aquellas ermitas que no tuvieran licencia de los obispos y que en adelante se estudiara con atención las solicitudes de nuevas edificaciones.

Un cura del obispado de Puebla insistía en que la única manera de evangelizar a los indios, estando tan distantes unos de otros, era reunirlos en un sólo punto, si bien pedía tener cuidado de no sacarlos de su región y su clima. Este ministro señaló que en su partido había seis o siete barrios y varios caseríos más que debían reunirse en un solo poblado y que en el partido vecino de Hueytlapan la mayoría de los indios vivían en montes y quebradas todavía. Todo ello provocaba ofensas a Dios, como en la provincia de Tlatlauquitepec, en donde los indios vivían en montes y orillas de ríos viviendo como bárbaros ${ }^{72}$.

68 Manuscritos del concilio tercero provincial mexicano (1585), 2006, primer tomo, vol. I, p. 295.

69 Ibídem, p. 295.

70 La importancia de esta propuesta para el concilio queda señalado con un texto que se escribió al margen: "Inmediatamente consta su vista en 30 de enero de 1585 en el concilio y su decreto: de que se oye y se ponga en los memoriales para que se provea lo que convenga al servicio de Dios”. Ibídem, p. 387.

71 Ibídem, p. 391.

72 Ibídem, p. 449. 
Jerónimo de Mendieta, sin duda uno de los líderes franciscanos más connotados de la época, se volvió a hacer presente insistiendo en que antes de hacerse las reducciones las autoridades debían salvaguardar sus tierras:

Lo que siento están obligados los señores obispos a avisar a su majestad que es muy necesario para la cristiandad de los indios y para poderlos bien gobernar en lo temporal, hacer juntar por orden y traza de calles alrededor de las iglesias a los que están derramados, porque de otra suerte ni los ministros se podrán recoger para su doctrina, ni los que los gobiernan se podrán averiguar con ellos, y entiéndese que esta junta se haga sin daño de sus tierras amparándolos en ellas ${ }^{73}$.

Como es posible advertir hasta aquí, si bien seculares y regulares concidían en la necesidad de una congregación general para acabar de consolidar la fe de los indios y su vida política y racional, según los parámetros hispánicos, las diferencias siguieron manifestándose. Los franciscanos no condenaban propiamente la forma dispersa de vivir de los indios pues la justificaban en torno al derecho de los indios por defender sus tierras; de ahí su insistencia en que las autoridades virreinales debían salvaguardar ese derecho antes de forzar una congregación general. Además, los religiosos defendían la existencia de tantos pueblos sujetos a cabeceras de doctrina como fueran necesarios para que los indios pudieran conservar sus tierras. En cambio, para el clero secular, comenzando por los arzobispos de México, la dispersión no era sino una fuente de pecados permanentes y por tanto nada justificaba su vigencia; de hecho, veían como algo necesario también el traspaso de tierras desocupadas a los colonos españoles dada la necesidad de su arraigo a Nueva España.

\section{EL DECRETO RESULTANTE DEL TERCER CONCILIO}

Puesto que en el tercer concilio mexicano sólo se dedicó un decreto al tema de las congregaciones, podría pensarse en primera instancia que hubo poco interés en el asunto. Sin embargo, con lo expuesto en las páginas anteriores es indudable que ambos cleros deseaban pueblos más congregados, concientes de que ello aceleraría la conversión religiosa de la población nativa. La normativa conciliar obligaba a los curas de almas a desarrollar toda una serie de actividades de catequesis y organización parroquial que se hacia casi imposible si antes no se congregaban los fieles. Además, cabe recordar que con la fatal epidemia de 1576 "muchas estancias e inclusive algunas cabeceras quedaron con sólo unos cuantos habitantes" ${ }^{\text {" }}$. Es decir, lo logrado por los religiosos y el virrey Velasco entre 1550 y 1564 en materia de reducciones se vio afectado por la caída demográfica indígena, por lo cual el asunto de congregar volvío a tomar mucha fuerza en la década previa al tercer concilio.

\footnotetext{
73 "Lo que siento están obligados los señores obispos a avisar a su majestad que es muy necesario para la cristiandad de los indios y para poderlos bien gobernar en lo temporal, hacer juntar por orden y traza de calles alrededor de las iglesias a los que están derramados". Ibídem, p. 460.

74 Gibson, 1991, p. 387.
} 
El decreto de congregación del tercer concilio provincial mexicano puede ser interpretado como una toma de postura uniforme de los obispos novohispanos con respecto al problema de la organización residencial de los indios. En efecto, el decreto intitulado "Sujétese a los indios a la vida civil y social, y a este fin congrégueseles en pueblos" 75 , manifiesta una preocupación muy vigente que expresaba los objetivos generales de las congregaciones y los efectos que buscaba paliar, sin entrar en detalles sobre lo logrado en las décadas anteriores. Así, el decreto refleja la preocupación generalizada por reducir más a los indios, poniendo como principal responsable al virrey y como auxiliares a los obispos, sin mencionar en ninguna línea a los religiosos.

Una lectura literal del decreto puede dejar la impresión de que la población indígena aun vivía como en la época prehispánica y que no se había hecho nada al respecto, que los indios seguían conservando sus "bárbaras costumbres" huyendo del "trato civil" y la doctrina cristiana:

los indios habitan dispersos en lugares ásperos y montañosos, y que huyen del trato civil y comunicación de los hombres, de lo que resulta que ni deponen sus bárbaras y crueles costumbres ${ }^{76}$.

Es evidente que los obispos no reconocían ningún avance logrado, poco o mucho, en años anteriores por los frailes y el virrey Luis de Velasco. En cambio, critican que los últimos virreyes no hubiran obedecido las órdenes de la Corona: "cuya sabia disposición no se ve que se haya puesto en ejecución" 77 . Por ello, les pedían actuar indefectiblemente, haciendo a un lado "todo impedimento secular" ${ }^{\text {" }}$. ¿Crítica velada al virrey Luis de Velasco, quien había actuado de la mano de los religiosos, más que de los clérigos?

Sin duda, para los autores del concilio eran injustificables las razones de los indios para permanecer en sus tierras, sus recursos y sus formas tradicionales de vida. Igualmente, los conciliares callaban cualquier alusión al torrente de críticas que los religiosos habían impulsado, criticando duramente los servicios personales forzados a los españoles y su residencia entre pueblos de indios. Para los obispos, pues, todo estaba por hacerse para civilizar y cristianizar a los indios.

Otro aspecto a destacar de ese decreto es que los obispos se erigían como los grandes auxiliadores de las congregaciones, buscando una mayor autoridad y presencia social y desconociendo cualquier participación de los frailes: "A los prelados también amonesta este sínodo a que presten todo el auxilio que les sea posible para que se lleve a cabo esto, de lo que depende la conversión de los indígenas, y la reforma de costumbres en esta provincia"79. A tono con las nuevas directrices tridentinas, enuncian

75 Tercer concilio y Directorio, 2004, libro I, título I, parágrafo III: "Sujétese a los indios a la vida civil y social, y a este fin congrégueseles en pueblos".

76 Ibídem.

77 Ibídem.

78 "Exhorta cuanto puede en el Señor a los gobernadores, que en estas partes fungen las veces de su majestad católica para que, removido todo impedimento secular y con ánimo verdaderamente piadoso y cristiano, trabajen en este negocio, y no se hagan responsables de que no tenga el debido efecto este justísimo decreto del rey". Ibídem.

79 Ibídem. 
la estrecha relación de congregar y reformar las costumbres de los naturales. Para finalizar el decreto en cuestión los obispos lo vincularon con los intereses monárquicos; de la congregación dependía también el cumplimiento de la cédula del patronato de 1574, "porque si esto no tiene efecto, ni su majestad católica podrá satisfacer a lo que exige el real derecho del patronato" 80 .

Paralelamente, los autores del concilio enviaron un largo memorial al rey que ampliaba y ratificaba los argumentos vertidos en el decreto conciliar; en el mismo afirmaban que el emperador Carlos $\mathrm{V}$ ya había ordenado la congregación por varias cédulas, tanto en Nueva España como en Perú, pero mientras en este virreinato sí se había cumplido, obteniendo los indios mucho provecho, en el primero no, sin que los virreyes Enríquez ni Coruña hicieran algo al respecto. Por ello, agregaban, el concilio quiso ayudar al dedicar un decreto al asunto, denunciando los perjuicios de la inoperancia y solicitando a los gobernadores la pronta ejecución de las reales órdenes. Pedían al rey, por todo lo anterior, ordenar a sus ministros la pronta ejecución de la congregación general y repartir los indios entre clérigos y frailes, de manera que cada ministro tuviera el "número de indios que competentemente pueda administrar y doctrinar dándole estipendio suficiente" ${ }^{81}$. El mensaje era claro: con la congregación general se podría también redistribuir de manera homogénea los curatos a ambos cleros, como en Perú. Al año siguiente del tercer concilio, 30 de mayo de 1586, los religiosos enviaron un informe al rey insistiendo en dotar a los indios de tierras suficientes paralelamente a que se efectuara la congregación general ${ }^{82}$.

\section{REFLEXIONES FINALES}

La congregación de la población indígena del siglo XVI fue un proceso muy complejo que involucró no sólo a las autoridades virreinales y los religiosos sino también a la Iglesia secular. Es claro que en las primeras tres décadas después de la conquista hubo dudas y reticencias para emprender una reducción general pues esto iba en contra, tanto de la conservación de los señoríos indígenas fomentada por entonces como de la libertad de movimiento de los indios decretada por la Corona. Si bien comenzaron a hacerse algunas reducciones, principalmente a iniciativa de algunos religiosos, los resultados fueron muy relativos.

Aunque la primera generación de obispos, en la década de 1530, comenzó a manifestar su interés en impulsar una congregación general, aun carecía de una presencia política importante como para incidir en las decisiones de gobierno; en la práctica, los frailes siguieron definiendo los pasos a seguir. Sin duda, fue esa una época de ensayos y reajustes constantes que involucró la formación de doctrinas y curatos, y que, según lo estudiado hasta ahora, no se alcanzó cierta estabilidad sino hasta las congregaciones de principios del siglo XVII. Pero además el interés por las congregaciones, del clero regular y del secular poco después, iba más allá del puro interés evangelizador.

\footnotetext{
80 Ibídem.

81 Manuscritos del concilio tercero provincial mexicano (1585), 2006, primer tomo, vol. I, p. 141.

82 CARTAS..., 1866, p. 154.
} 
Los frailes defendían formas de poblar de los indios que les permitiera conservar todas sus tierras, ante el avance de los labradores españoles e implícitamente conservar el poder de las grandes doctrinas fundadas por los primeros. Los obispos, en cambio, impulsaron la formación de poblaciones de indios más grandes y compactas, para evitar la proliferación de cientos de pueblos sujetos a cabeceras, por un lado, y favorecer la liberalización de tierras para los colonos, por el otro, confiando en adjudicarse muchos curatos de nueva creación.

Los cambios sociales y políticos de mediados del siglo XVI favorecieron el proyecto de los religiosos. El virrey Luis de Velasco y los frailes coincidieron en establecer congregaciones parciales, tratando de proteger las doctrinas ya establecidas así como la posesión de las tierras por los indios. Para ello se reforzó una solución intermedia: congregar, no sólo en las cabeceras sino en nuevos pueblos sujetos, que proliferaron en todas aquellas provincias visitadas. Esta solución no satisfizo a los obispos quienes, más fortalecidos bajo el liderazgo del arzobispo Alonso de Montúfar, pidieron la congregación general en el primer concilio de la provincia mexicana en 1555. El surgimiento gradual de más curatos diocesanos fortaleció el involucramiento del clero secular en el asunto. Con todo, entre 1550 y 1580, las congregaciones parciales impulsadas por los religiosos, basadas en el modelo cabecera-sujetos, fue lo que predominó, a pesar de las presiones de los obispos porque la Corona ordenara formar pueblos más grandes en todo el territorio novohispano así como evitar la proliferación de pequeños poblados sujetos a cabeceras parroquiales o de doctrina.

Es en ese contexto en el que se realizan las discusiones y propuestas en el tercer concilio mexicano de 1585 , en donde volvieron a discutirse dos modelos de congregación: la practicada hasta entonces por los religiosos y que apoyó decididamente el virrey Velasco, o bien, la propuesta por el jesuita Juan de la Plaza basada en lo prácticado en varias regiones de Perú, a saber: formación de pueblos uniformes, tanto en número de fieles, 500, y de ministros encargados, prescindiendo de poblados sujetos, todo bajo el mando de funcionarios reales nombrados ex profeso para la empresa. La propuesta de Plaza, sin duda, compaginaba mejor con la opinión del arzobispo de México Moya de Contreras sobre una mayor desocupación de tierras por los indios para favorecer a labradores españoles.

Al final, se redactó un solo decreto sobre congregaciones que reflejaba sumariamente el pensamiento de la Iglesia secular. Si bien en ese decreto no se propuso alguno de los dos modelos discutidos, el hecho de haberse omitido o desconocido lo logrado hasta entonces por los religiosos reflejó una mayor simpatía por la solución peruana, algo ratificado en una carta separa enviada por entonces a la Corona también. La parte medular del decreto consistió en pedir a Felipe II el cumplimiento inmediato de la congregación general, reprochando de paso a los virreyes la falta de una solución integral. Cabe destacar que los obispos pidieron que fuera la Corona y sus ministros quienes se hicieran cargo de la congregación general, omitiendo cualquier participación de los religiosos en el asunto.

Un año después del tercer concilio, en 1586, los religiosos, concientes de las mayores posibilidades de que la Corona ordenara esa campaña general de congregaciones, siguieron insistiendo en que su realización no podía desligarse del problema de la tierra de los indios y sus formas de organización social, económica y política, 
dejando ver así su rechazo al modelo peruano. Cuando en la última década del siglo XVI la Corona por fin emprendió una campaña general de congregaciones por toda la Nueva España, la tendencia fue respetar, en efecto, el modelo que el virrey Velasco y los frailes practicaron desde la década de 1550 .

En el futuro habrá que analizar de una manera más sistemática el impacto del proceso de reducciones en el establacimiento de la red parroquial de cada diócesis. Sin duda, el gran reto para frailes y clérigos fue convertir esas congregaciones de indios forzados a vivir juntos, en muchas ocasiones con diferencias culturales y lingüísticas, en comunidades de fieles con una identidad común y con un sentido de pertenencia parroquial. La congregación general de fines del siglo XVI y principios del XVII fue, en este sentido, el inicio de otro proceso de más largo aliento.

\section{REFERENCIAS BIBLIOGRÁFICAS}

Aguirre beltrán, Hilda

1984 La congregación civil de Tlacotepec (1604-1606). México. CIESAS.

CARTAS

1877 Cartas de Indias. Madrid. Imprenta de Manuel G. Hernández.

1886 Cartas de religiosos de Nueva España, 1539-1594. Nueva colección de documentos para la historia de México I. México. Imprenta de Francisco Díaz de León.

Cline, Howard F.

1949 "Civil congregatios of the indians in New Spain 1598-1605". Hispanic American Historical Review. Durham, nº XXIX, pp. 349-369.

Concilios

2004a “I y II Concilios". Estudio introductorio, trascripción paleográfica y anexos de PÉREZ Puente, Leticia - González González, Enrique - Aguirre Salvador, Rodolfo. En Martínez LóPEz-CANo (coord.). Concilios provinciales mexicanos. Época colonial. México. Instituto de Investigaciones Históricas - Universidad Nacional Autónoma de México. Disco compacto.

2004b “III concilio y Directorio". Estudio introductorio, trascripción paleográfica y anexos de Martínez López-Cano, María del Pilar - García Berumen, Elisa Itzel - García Hernández. En Martínez López-Cano (coord.). Concilios provinciales mexicanos. Época colonial. México. Instituto de Investigaciones Históricas - Universidad Nacional Autónoma de México. Disco compacto.

2006 Manuscritos del concilio tercero provincial mexicano (1585). Edición, estudio introductorio, notas, versión paleográfica y traducción de textos latinos por CARRILLO CÁzARES. Guadalajara. El Colegio de Michoacán - Universidad Pontifica de México, tomo I, vol. I.

De la Torre Villar, Ernesto

1952 "Las congregaciones de indios en el siglo XVI. Relación de la congregación del pueblo de Tianguistengo". Boletín del Archivo General de la Nación, México, Tomo XXIII, no 2, pp. 145-213.

1994 "Las congregaciones de indios como una fase de la política de población y colonización en América". Estudios de Historia Jurídica. México. Universidad Nacional Autónoma de México, pp. 117-138. Consultado el 21 de mayo de 2012 en: http://biblio. juridicas.unam.mx/libros/2/812/10.pdf. 
DESCRIPCIÓN

1976 Descripción del arzobispado de México hecho en 1570 y otros documentos. AviÑA LEVy (ed.). Guadalajara. Biblioteca de facsímiles Mexicanos.

GARcía ICAZBALCETA, Joaquín (ed.)

1889 Nueva colección de documentos para la Historia de México II. Códice franciscano siglo XVI. México. Imprenta de Francisco Díaz de León.

García Martínez, Bernardo

2000a "La transformación de los pueblos". Historia general de México. México. El Colegio de México, pp. 290-291.

2000b "La Junta Magna y sus secuelas”. Historia general de México. México. El Colegio de México, 2000, pp. 298-300.

Gerhard, Peter

1977 “Congregaciones de indios en la Nueva España antes de 1570”. Historia Mexicana. México, Vol. XXVI, nº 3. pp. 347-395.

GiBson, Charles

1991 Los aztecas bajo el dominio español. México. Siglo XXI.

JALPA Flores, Tomás

1993 "La congregación de pueblos en la provincia de Chalco: reorganización del espacio administrativo, siglo XVI-XVII. En TorTolero (coord.), Entre lagos y volcanes. Chalco-Amecameca: pasado y presente. México. El Colegio Mexiquense - Ayuntamiento de Chalco, Vol. I. Vol. I. pp. 149-193.

JuRAdo, Carolina

2004 "Las reducciones toledanas a pueblos de indios: aproximación a un conflicto. El repartimiento de Macha (Charcas), siglo XVI". Cahiers des Amériques Latines. París, n47, pp. 123-132.

Lopetegui, León - Zubillaga, Félix

1965 Historia de la Iglesia en la América Española. Desde el Descubrimiento hasta comienzos del siglo XIX. México. América Central. Antillas. Madrid. Biblioteca de Autores Cristianos.

Málaga Medina, Alejandro

1993 "Las reducciones toledanas en el Perú”. En Gutiérrez, RAmón (coord), Pueblos de indios. Otro urbanismo en la región andina. Quito. Ediciones Abya-Yala, pp. 263-316.

Martínez López-Cano, María del Pilar - Cervantes Bello, Francisco (coords.)

2005 Los concilios provinciales en Nueva España. Reflexiones e influencias. México. Universidad Nacional Autónoma de México - Benemérita Universidad Autónoma de Puebla.

Mendieta, Gerónimo de

2002 Historia Eclesiástica. México. Consejo Nacional para la Cultura y las Artes. 2 tomos.

Menegus, Margarita

1991 Del señorío a la república de indios. El caso de Toluca: 1500-1600. Madrid. Ministerio de Agricultura, Pesca y Alimentación.

Morales, Francisco

2010 "La Iglesia de los frailes". En Menegus - Morales - Mazín, La secularización de indios en la Nueva España. La pugna entre las dos iglesias. México. Instituto de Investigaciones sobre la Universidad y la Educación - Universidad Nacional Autónoma de México, pp. 13-76. 
Pérez Puente, Leticia

2010 El concierto imposible. Los concilios provinciales en la disputa por las parroquias indigenas (México, 1555-1647). México. Instituto de Investigaciones sobre la Universidad y la Educación - Universidad Nacional Autónoma de México.

Rubial, Antonio

1989 El convento agustino y la sociedad novohispana (1533-1630). México. Universidad Nacional Autónoma de México.

RuBio MAÑé, Ignacio

1955 "Congregaciones civiles de indios en Nueva España, 1598-1609”. Boletín del Archivo General de la Nación. México, tomo XXVI, n² 2, pp. 197-216. 